- Orijinal Makale

\title{
Solunumsal yoğun bakım ünitesinde perkütan endoskopik gastrostomi deneyimlerimiz
}

\section{Percutaneous endoscopic gastrostomy experiences in the respiratory intensive care unit}

\author{
Güler ERASLAN DOĞANAY* —, Mustafa Özgür CIRIK 투
}

Sağlık Bilimleri Üniversitesi, Atatürk Göğüs Hastalıkları ve Göğüs Cerrahisi Eğitim Araştırma Hastanesi, Anesteziyoloji ve Reanimasyon, Ankara/TÜRKIYE

\section{öz}

Amaç: Yoğun bakım hastalarının beslenmesi önemli olmasına rağmen çoğu yatış endikasyonları sebebiyle oral beslenmede zorluk yaşamaktadır. Beslenme çoğunlukla nazogastrik tüp, perkütan endoskopik gastrostomi (PEG) ve parenteral beslenme şeklinde sağlanabilmektedir. Bu çalışmada yoğun bakımda beslenme amaçlı PEG açılan hastaları retrospektif olarak değerlendirmeyi amaçladık.

Gereç ve Yöntem: Çalışmaya solunumsal yoğun bakım ve palyatif bakım servisinde 2018-2020 yılları arası takip edilen ve beslenme için PEG açılan hastalar dahil edilmiştir. Hastaların yaş, cinsiyet, hastanede yatış süresi, trakeostomi durumu, ev tipi mekanik ventilatör durumu, PEG işlemi i lişkili komplikasyonları ve bir aylık mortaliteleri retrospektif olarak incelenmiştir.

Bulgular: Hastaların 18'i $(\% 54,5)$ erkek, 15'i $(\% 45,5)$ kadındı. Ortalama yaş $71 \pm 19$ olarak bulundu. PEG açılan hastaların çoğunluğunun yatış tanısı nörolojik hastalıklardı (Alzheimer ve geçirilmiş serebro vasküler hastalık). PEG ilişkili komplikasyon sadece bir hastada görüldü.

Sonuç: PEG komplikasyon oranının düşük olması, hasta için efektif beslenme sağlaması ve yoğun bakımda hasta başı uygulanabilir bir işlem olması sebebiyle uzun süreli enteral beslenme gereken hastalarda tercih edilmelidir.

Anahtar Kelimeler: Yoğun bakım; Perkütan endoskopik gastrostomi; Enteral beslenme

Sorumlu Yazar*: Güler Eraslan Doğanay, Sağlık Bilimleri Üniversitesi, Atatürk Göğüs Hastalıkları ve Göğüs Cerrahisi Eğitim Araştırma Hastanesi, Anesteziyoloji ve Reanimasyon, Ankara/TÜRKIYE

E-posta: gulerdoganay@hotmail.com.tr ORCID: 0000-0003-2420-7607

Gönderim: 09.03.2021 kabul: 06.10.2021

Doi: $10.18663 /$ tjcl.893540 


\section{ABSTRACT}

Aim: Although nutrition of intensive care patients is important, difficulties are experienced in oral nutrition due to hospitalization indications. Nutrition can be mostly provided by nasogastric tube, percutaneous endoscopic gastrostomy (PEG) and parenteral nutrition. In this study, we aimed to retrospectively evaluate patients who underwent PEG for nutritional purposes in the intensive care unit.

Materials and Methods: Patients who were followed up in our respiratory intensive care and palliative care unit between 2018-2020 and had PEG for nutrition were included in the study. Age, gender, length of hospital stay, tracheostomy status, home ventilator status, PEG related complications and one-month mortality were retrospectively analyzed.

Results: The 18 (54.5\%) of the patients were male, 15 (45.5\%) were female. The mean age was $71 \pm 19$ years. Most of the PEG patients were diagnosed with neurological diseases (Alzheimer and cerebro vascular disease). PEG related complication was only seen in a patient.

Conclusion: PEG should be preferred in patients who require long-term enteral nutrition because of its low complication rate, providing effective nutrition for the patient, and being a bedside procedure in the intensive care unit.

Keywords: Intensive care; Percutaneous endoscopic gastrostomy; Enteral nutrition.

\section{Giriş}

Perkütan endoskopik gastrostomi (PEG) işlemi 1980 yılından beri kullanılan bir yöntem olup prosedürle ilgili pek çok farklı yöntem tanımlanmıştır[1].Yoğun bakım hastalarında beslenme önemli olup hastanın günlük kalori ihtiyacının altında kalması morbidite ve mortalitesinde etkileyen önemli bir faktördür [2]. Enteral beslenme; intestinal mukozanın bütünlüğünü koruyarak, immunitenin korunması ve enfeksiyonlara karşı direnç göstermeye olanak sağlar. Kısa süreli enteral beslenme uygulaması için nazogastrik tüp kullanımı uygun olsa da, uzun dönem enteral beslenme desteği için hastalara daha çok PEG uygulaması tercih edilmektedir [1,2].

\section{Gereç ve Yöntemler}

Yoğun bakım ve palyatif bakım ünitemizde 2018-2020 yılları arasında takip edilen ve PEG açılmış olan 33 hasta retrospektif olarak incelendi. Hastaların yaşları, cinsiyetleri, ana tanıları, trakeostomi ve ev tipi mekanik ventilatör durumları, gelişen PEG ilişkili komplikasyonlar, bir aylık mortaliteleri kayıt altına alındı. Çalışma için Atatürk Göğüs Hastalıkları ve Göğüs Cerrahisi Eğitim ve Araştırma Hastanesi'nden etik kurul onayı (04.03.2021/216) alındı.

\section{İstatistiksel Analiz}

İstatistiksel analizde SPSS 21.0 programı kullanıldı. Çalışmamız tanımlayıcı nitelikte olup sürekli değişkenler ortalama \pm standart sapma, medyan (minimum ve maksimum değerler) ve kategorik değişkenler sayı, yüzde olarak ifade edilmiştir. Kategorik değişkenler arasındaki farklııklar Ki-kare analizi ile incelenmiştir. Tüm analizlerde $p<0,05$ istatistiksel olarakanlamlı kabul edilmiştir. Bağımsı değişkenlerin karşılaştırılmasında Mann-Whitney U testi kullanılmıştır.

\section{Bulgular}

Çalışmaya dahil edilen 33 hastanın 18'i $(\% 54,5)$ erkek, 15'i $(\% 45,5)$ kadındı. Ortalama yaş $71 \pm 19$ olarak bulundu. PEG işlemi uygulanan hastaların ana tanıları Tablo 1 'de belirtilmiştir. PEG açılan hastaların çoğunluğunun ana tanıları nörolojik hastalıklar olup (n:25, \%75,7), $9(\% 27,3)$ hasta Alzheimer, 6 $(\% 18,2)$ hasta geçirilmiş serebro vasküler hastalık (SVO), 1 $(\% 3,03)$ hasta epilepsi, $1(\% 3,03)$ hasta Multiple Skleroz (MS), 7 $(\% 21,2)$ hasta Amniyotrofik Lateral Skleroz (ALS), $1(3,03)$ hasta Subakut Sklerozan Panensefalit (SSPE) idi.

\begin{tabular}{|c|c|c|c|}
\hline Ana Tanı & $\begin{array}{l}\text { Kadın Hasta } \\
\text { Sayı (n) (\%) }\end{array}$ & $\begin{array}{l}\text { Erkek Hasta } \\
\text { Sayı (n) (\%) }\end{array}$ & $\begin{array}{l}\text { Toplam } \\
\text { Sayı (n) (\%) }\end{array}$ \\
\hline Nörolojik & $13(39,3)$ & $12(36,3)$ & $25(75,7)$ \\
\hline $\begin{array}{l}\text {-Alzheimer } \\
\text {-Geç. SVO } \\
\text {-Epilepsi } \\
\text {-MS } \\
\text {-ALS } \\
\text {-SSPE }\end{array}$ & $\begin{array}{l}5(15,1) \\
3(9,0) \\
0(0) \\
1(3,0) \\
3(9,0) \\
1(3,0)\end{array}$ & $\begin{array}{l}4(12,1) \\
3(9,0) \\
1(3,0) \\
0(0) \\
4(12,1) \\
0(0)\end{array}$ & $\begin{array}{l}9(27,3) \\
6(18,2) \\
1(3,0) \\
1(3,0) \\
7(21,2) \\
1(3,0)\end{array}$ \\
\hline Post CPR* & $1(3,0)$ & $5(15,1)$ & $6(18,1)$ \\
\hline Konjenital hastalık & $1(3,0)$ & $1(3,0)$ & $2(6,0)$ \\
\hline \multicolumn{4}{|c|}{$\begin{array}{l}\text { Geç. SVO:Geçirilmiş Serebrovaskuler olay SSPE:Subakut sklerozan } \\
\text { panensefalit MS:Multiple Skleroz ALS: Amniyotrofik Lateral Skleroz } \\
\text { *Kronik obstruktif akciğer hastalığı(KOAH) nedeniyle gelişen kardi- } \\
\text { yak arrest sonrası resüsitasyon (post-CPR) }\end{array}$} \\
\hline
\end{tabular}


$8(\% 24,2)$ hastaya Kronik Obstruktif Akciğer Hastalığı (KOAH) sebebiyle kardiyak arrest ardından kardiyo-pulmoner resusitasyon sonrası gelişmiş hipoksik ensefalopati nedeniyle PEG işlemi uygulanmıştı. 2 (\%6) hastada ise konjenital genetik hastalık nedeniyle ilerleyici solunum güçlüğü ve kas kuvvet yetersizliği gelişmiş ve bu sebeple PEG açılmıştı.

Hastalarımızın \%97'sinde $(n=31)$ işlem sırasında veya sonrasında herhangi bir komplikasyon gelişmemiş olup, 1 hastamızda (\%3) lokal enfeksiyon görülmüştür.

Hastaların 22'si $(\% 66,7)$ trakeostomize-ev tipi mekanik ventilatör takipliydi, 1 (\%3) kişi spontan solunumu olan trakeostomili hastaydı, $10(\% 30,3)$ hastanın ise spontan solunumu mevcuttu. Kadınlarda; alzheimer $5(\% 15,1)$ kişide, SVO 3 (\%9) kişide, MS 1(\%3) kişide, ALS 3 (\%9) kişide, SSPE 1(\%3) kişide, KOAH post CPR 1(\%3) kişide, konjenital hastalık 1(\%3) kişide mevcuttu.

Erkeklerde; Alzheimer 4 (\%12,1) kişide, SVO 3 (\%9) kişide, Epilepsi 1(\%3) kişide, ALS 4 (\%12,1) kişide, KOAH post CPR $5(\% 15,1)$ hastada, konjenital hastalık $1(\% 3)$ kişide mevcuttu.

Hastanede yatış süresi ortalama $30 \pm 17$ gün olarak saptandı. Kadınlarda hastanede yatış günü ortalama $28 \pm 15$ günken, erkeklerde $34 \pm 14$ gün olarak bulundu. Cinsiyet ve hastanede yatış süresi arasında istatistiksel anlamlılık tespit edilmemiştir( $p=0,832)$.

Çalışmamızda işleme bağlı olduğunu düşündüğümüz mortalite görülmedi. İşlem yaptığımız hastaların 5'i $(\% 15,1)$ işlem sonrası 30 gün içinde primer hastalığa bağlı olarak mortal seyretti.

\section{Tartışma}

PEG işlemi uzun süre oral beslenemeyecek olan hastaların beslenmesinde öncelikli yol olarak tercih edilir. Alternatif yollar olan nazogastrik tüp ve parenteral beslenmeye göre belirgin üstünlükleri mevcuttur. Nazogastrik tüpte gelişebilecek komplikasyonlar olan malpozisyon, sürekli değiştirme ihtiyacı ve en önemlisi supin pozisyonda belirgin artmış olan aspirasyon riskini PEG azaltır. Ayrıca hastalar için daha fizyolojik beslenme olanağı sağlar. Parenteral beslenmede ise belirgin bir maliyet yüksekliği, fizyolojiye uygunsuzluk ve artmış enfeksiyon riski mevcuttur $[3,4]$.

PEG işlemi ihtiyacının çoğunlukla sebebi nörolojik kaynaklı olup literatürde en sık sebep olarak geçirilmiş SVO (\%5075) gösterilmiştir [5,6]. Bu çalışmada da PEG endikasyonu için en sık sebep $\% 75,7^{\prime}$ i ile nörolojik kaynaklı hastalıklardı
(Alzheimer, ALS, SVO, MS, SSPE). İzole SVO'ya bağlı PEG işlem oranı çalışmamızda \%18,2'dir. Bunun sebebi hastanemizin göğüs hastalıkları dal hastanesi olması ve daha çok solunum yolu hastalıklarına bağlı yoğun bakım yatışı olması olabilir. ALS ve alzheimer gibi hastalıklarda ilerleyici solunum güçlüğü, ventilasyonda bozulma sebebiyle mekanik ventilatöre bağlı hasta oranı artmakta ve bu grup hastalarda beslenme için PEG işlemi tercih edilmektedir.

PEG işlemi 1980 yılından beri yaygın olarak kullanılmaktadır. Cerrahi ve endoskopi olmak üzere farklı iki teknikle yapılabilirken, endoskopik işlem cerrahiye göre hem süre hem enfeksiyon oranının azlığı sebebiyle tercih edilmektedir. Komplikasyonları arasında kanama, enfeksiyon, tıkanma, diyare sayılabilir. Hastalarımızdan sadece 1'inde lokal enfeksiyon saptanmış olup lokal pomad uygulamasından fayda görmüştür. Literatürde kanama sıklığı \%18, enfeksiyon sıklığı ise \%15 olarak tespit edilmiştir [6,7].

PEG ile ilişkili mortalite \%1'in altında bildirilmiştir. İşlem sonrası 30 günlük mortalite oranları yurt dışı serilerde $\% 8-20$, ülkemizde ise \%10-26,8 olarak bildirilmiştir [4]. Çalışmamızda işleme bağlı olduğunu düşündüğümüz mortalite görülmedi. İşlem yaptığımız hastaların $5^{\prime} \mathbf{i}(\% 15,1)$ işlem sonrası 30 gün içinde primer hastalığa bağlı olarak mortal seyretti.

Çalışmalarda PEG açılmasının, hastalarda aspirasyon riskini düşürerek enfeksiyon oranlarını azalttığı ve bu sayede yaşam kalitesini arttırdığı da bildirilmiştir [8].

\section{Sonuç}

PEG işlemi uzun dönem oral beslenemeyen hastalar için ilk tercihtir. Komplikasyon oranının oldukça düşük olması, hasta için efektif beslenme sağlaması ve yoğun bakımda hasta başı uygulanabilir işlem olması sebebiyle tercih edilmelidir.

\section{Çıkar çatışması/finansal destek beyanı}

Çalışmayı maddi olarak destekleyen kişi/kuruluş yoktur ve yazarların herhangi bir çıkara dayalı ilişkisi yoktur.

\section{Kaynaklar}

1. Marik PE, Zaloga GP. Early enteral nutrition in acutely ill patients: a systematic eview. Crit Care Med 2001; 29: 2264-70.

2. İnanc $Y$, Gokce $M$, Tuncel $D$, et al. Percutaneous endoscopic gastrostomy in neurology intensive care. International Journal of Surgery and Medicine 2018; 4 :33-5.

3. Öcek, et al. PEG in the Neurology Intensive Care Unit Turk J Neurol 2020; 26: 30-3. 
4. Temiz A, Aslan $O B$, Albayrak $Y$, et al. Perkütan endoskopik gastrostomi: endikasyon ve komplikasyonlar.Akademik Gastroenteroloji Dergisi 2015; 14 :113-6.

5. Tian Y, Du HG, Fan CP, et al. Clinical significance of percutaneous endoscopic gastrostomy for patients with severe cranio cerebral injury. Chin J Traumatol 2014; 17: 341-4.

6. Schurink CA, Tuynman $H$, Scholten $P$, et al. Percutaneous endoscopic gastrostomy: Complications and Suggestion to avoid them. Eur J Gastroenterol Hepathol 2001; 13: 819-23.
7. Sanders DS, Carter MJ, D'Silva J, et al. Survival analysis in percutaneous endoscopic gastrostomy feeding: a worse outcome in patients with dementia. Am J Gastroenterol 2000; 95: 1472-5.

8. Kahraman A. Two multiple sclerosis patient presented with dysphagia who underwent percutaneous gastrostomy in palliative carecenter. Van Medical Journal 2017; 24: 382-3. 